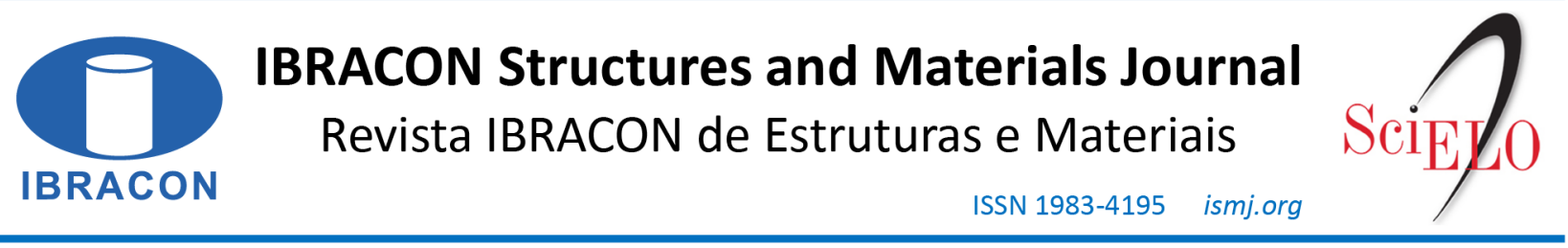

ORIGINAL ARTICLE

\title{
Incorporation of recycled aggregates from construction and demolition waste in paver blocks
}

\section{Desempenho de blocos de concreto com incorporação de agregados reciclados provenientes de resíduos de construção e demolição}

\author{
Cinthia Maia Pederneiras ${ }^{\mathrm{a}}$ (D) \\ Maria Del Pilar Durante ${ }^{\mathrm{a}}$ (iD \\ Ênio Fernandes Amorim ${ }^{b}$ (1) \\ Ruan Landolfo da Silva Ferreira ${ }^{\mathrm{c}}$

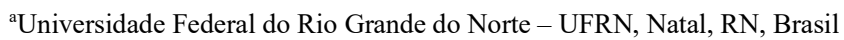 \\ ${ }^{b}$ Instituto Federal do Rio Grande do Norte - IFRN, Natal, RN, Brasil \\ 'Instituto Federal de Educação, Ciência e Tecnologia de Pernambuco - IFPE, Pesqueira, PE, Brasil
}

Received 23 August 2018

Accepted 28 January 2020

\begin{abstract}
The consumption of natural resources and energy increased proportionally with the growth of the world population and its economic level. There was an increasing exponential consumption of natural resources, which implied an increase in environmental impacts. The construction sector is responsible for a very significant production of construction and demolition waste (CDW). Thus, there is a concern in search of a more sustainable final disposal. Many studies have been investigated the development of new materials with the incorporation of recycled aggregates from CDW. This paper presents a study of performance evaluation of concrete blocks produced with CDW. For that purpose, an experimental campaign was performed, including a characterization of the aggregates used. The incorporation of $100 \%$ of fine and coarse recycled aggregates. The mixtures were designed according to the condition of the aggregate (dry, washed or saturated). The performance of these blocks was evaluated in terms of mechanical strength and water absorption. Some additional tests were also performed to deeper analyze of the microstructure of these blocks. To assess the durability of the concrete blocks, a full-scale road was built. The results were very positive, since there were no significant differences between the modified concrete blocks and the reference sample $(0 \%$ of the $\mathrm{CDW})$. The modified block with fine aggregate presented the best performance of all the blocks, concerning mechanical strength. In addition, the performance of concrete blocks with washed recycled aggregates had a better performance compared to the others. The results obtained were satisfactory for the application of the blocks in the streets with low movement and low load.
\end{abstract}

Keywords: recycled aggregates, construction and demolition waste, paver blocks.

Resumo: O consumo de recursos naturais e energia aumentou proporcionalmente com o crescimento da população mundial e seu nível econômico. Houve um consumo exponencial crescente de recursos naturais, o que implicou em um aumento nos impactos ambientais. O setor da construção é responsável por uma produção muito significativa dos resíduos de construção e demolição (RCD). Dessa forma, evidencia-se uma preocupação em busca de destino final mais sustentável, com isso muitos estudos estão sendo feitos a fim de desenvolver novos produtos com a substituição de recursos naturais por RCD. Este trabalho pretende analisar o comportamento de blocos de concreto produzidos com RCD. Para isso, foi realizado um programa experimental, incluindo uma caracterização dos agregados utilizados. A substituição foi de $100 \%$ de agregados naturais miúdos e graúdos por agregados reciclados. As misturas foram projetadas de acordo com a condição do agregado (seco, lavado ou saturado). O desempenho destes blocos foi avaliado em termos de resistência mecânica e absorção de água. Alguns testes extras também foram formulados para entender a microestrutura desses blocos. Para avaliar a durabilidade dos blocos de pavimentação, foi realizada uma estrada em escala real. Os resultados da pesquisa foram muito positivos, uma vez que não houve diferenças significativas entre os blocos de concreto modificados e a amostra de referência ( $\% \%$ do RCD). Em termos mecânicos, o concreto modificado com agregado miúdo foi o que apresentou o melhor desempenho de todos

eiras. E-mail: cinthiamaiap@hotmail.com

Corresponding author: Cinthia Maia Pederneiras. E-mail: cinthiamaiap@hotmail.com

Financial support: The author gratefully acknowledges the support of the Brazilian Research Supporting Agency (CAPES).

Conflict of interest: Nothing to declare. 
os blocos. Além disso, o desempenho de blocos de concreto usando agregados reciclados lavados foi melhor em comparação com os outros. Os resultados obtidos foram satisfatórios para a aplicação dos blocos em ruas de baixo movimento e baixa carga.

Palavras-chave: agregados reciclados, resíduos de construção e demolição, blocos de pavimentação.

How to cite: C. M. Pederneiras, M. Pilar Durante, E. F. Amorim, and R. L. S. Ferreira, "Incorporation of recycled aggregates from construction and demolition waste in paver blocks," Rev. IBRACON Estrut. Mater., vol. 13, no. 4, e13405, 2020, https://doi.org/10.1590/S1983-

41952020000400005

\section{INTRODUCTION}

The construction industry has been considered one of the most waste producer and consumer of natural resources. This environmental concern encouraged the current trend of using recycled aggregates from construction and demolition waste for production of cementitious materials.

According to the Brazilian Association for Recycling of Construction and Demolition Waste (ABRECON) [1], in Brazil in the year of 2015 the estimated production of waste was approximately 85 million $\mathrm{m}^{3}$. The amount of recycled CDW was an average of 5 million $\mathrm{m}^{3}$.

The use of CDW as recycled aggregates is one of the most feasible solution. Several studies have been published about the use of recycled aggregate as replacement of natural sand. In this study, the performance of concrete blocks for interlocked paving with the incorporation of CDW as recycled aggregate is analyzed.

Researches have been developed to evaluate the use of recycled aggregates in concrete. From the literature, it can be verified that the materials produced with recycled aggregates achieve the required standards and specifications. Although, in some cases, there is a decrease in the mechanical strength. Particularly in the manufacture of concrete blocks [2]-[8], pre-cast cementitious products [9] and bricks [10].

Nonetheless, some authors have demonstrated an improvement on the mechanical properties of these materials with the use of recycled aggregate. Penteado et al. [11] observed an increase in compressive strength of the concrete blocks with recycled fine aggregates when compared to the reference blocks. Evangelista and Brito [12] justified these better results due the presence of non-hydrated cement particles in the recycled aggregate, which could contribute to a better bond between the cement paste and aggregates, due to their higher porosity. Rodriguez et al. [8] and Leite [13] studied the mechanical performance of concrete produced with recycled aggregates and obtained similar results.

On the other hand, the type of recycled aggregate affects differently the performance of the materials. Thus, Bravo et al. [14] highlighted an increase in impact resistance when coarse recycled aggregates were used in concrete blocks. Braga et al. [15] pointed out that the incorporation of fine recycled aggregates from CDW can increase the mechanical strength of the concrete due to the non-hydrated cement particles in the recycled material.

Bear in mind that the loss of mechanical strength is a limiting factor for the use of recycled aggregates, and it is higher when the water/cement ratio is lower [8], [16]. Notwithstanding the foregoing, some authors justified the increase of compressive strength in concrete with fine recycled aggregates due the pozzolanic effect of the fine particles [17], [18]

The higher content of fines in the recycled aggregates can improve the transition zone between the cementitious matrix and the aggregate, which contributes to a greater compactness of the concrete [19]. According to Lovato et al. [20] the fines particles provide a better packaging. As the recycled aggregate has higher absorption it promotes a greater adhesion between the cement paste and the aggregate, through the absorption of the paste and the precipitation of the crystals of hydration in the pores of the aggregate.

Another characteristic of the recycled aggregate that affects the concrete behavior is the presence of old mortar particles adhered to the grains. This could be related to a higher water absorption, higher porosity and lower resistance of the modified concrete [21]-[23].

In this research, the recycled aggregates were used in three different conditions, such as dried, washed and saturated. Rodrigues et al. [24] suggested to wash the aggregates to discard the fraction below $0.063 \mathrm{~mm}$, which can improve the quality of the recycled concrete produced. Poon et al. [25] recommended to saturate the recycled aggregate before mixing with the cement. This can reduce the water absorption of the aggregates.

Therefore, this research intends to analyze the performance of the concrete blocks with different conditions of the recycled aggregate. 


\subsection{Justification}

Considering the environmental impacts, it has been developed several researches about the use of recycled aggregates from $\mathrm{CDW}$. Therefore, this study presents a feasible product with the incorporation of recycled aggregate from $\mathrm{CDW}$.

\section{MATERIALS AND EXPERIMENTAL PROGRAM}

\subsection{Materials}

The following materials were used in this research: cement, sand, additive and water.

\subsubsection{Cement}

The binder used was cement type CP II-Z-RS, mainly used for the precast industry. The physical, mechanical and chemical properties are presented in Table 1.

Table 1. Characteristics of CP II-Z-RS.

\begin{tabular}{cc}
\hline Physical characteristics & \\
\hline Density $\left(\mathrm{g} / \mathrm{cm}^{3}\right)$ & 3.0 \\
\hline Blaine specif. area $\left(\mathrm{cm}^{2} / \mathrm{g}\right)$ & 4362 \\
\hline Initial set $(\mathrm{min})$ & 139 \\
\hline Final set $(\mathrm{min})$ & 191 \\
\hline Chemical characteristics & 4.41 \\
\hline $\mathrm{Al} 2 \mathrm{O} 3$ & 68.68 \\
\hline $\mathrm{CaO}$ & 2.35 \\
\hline $\mathrm{Fe} 2 \mathrm{O} 3$ & 1.26 \\
\hline $\mathrm{K} 2 \mathrm{O}$ & 2.70 \\
\hline $\mathrm{MgO}$ & 14.71 \\
\hline $\mathrm{SiO} 2$ & 0.33 \\
\hline $\mathrm{TiO} 2$ & 5.48 \\
\hline $\mathrm{SO} 3$ &
\end{tabular}

\subsubsection{Aggregates}

Both aggregates (fine and coarse) were separated in terms of their size, by sieving. The recycled aggregates were collected according to NBR NM 26 [26], dried in an oven $\left(105 \pm 5^{\circ} \mathrm{C}\right)$ for 48 hours and then cooled to the room temperature. After this procedure, they were submitted to the characterization tests. The fine fraction was sieved to remove particles over $4.75 \mathrm{~mm}$. The coarse aggregate was sieved to remove particles over $12.5 \mathrm{~mm}$ and smaller than $4.75 \mathrm{~mm}$.

\subsubsection{Additive}

The additive used was SikaPaver HC-10.

\subsection{Aggregates characterization}

The characterization tests were performed for natural and recycled aggregates (fine and coarse). The physical tests: size distribution [27], dry bulk density [28], [29], water absorption by capillarity [30], abrasion resistance Los Angeles [31], the superficial area of the fines of the aggregates determined from the physical adsorption of the nitrogen on the materials by the Brunauer-Emmett-Teller (BET) method, these analyzes were performed by the BEL JAPAN model BELSORP-mini II.

The chemical analysis was performed by the EDX-720 X-ray fluorescence spectrometer Shimadzu in a vacuum atmosphere and the semi-quantitative method was developed. The micrographs were obtained from Hitachi model TM-3000.MEV equipment. The X-ray diffractogram was performed for the mixed recycled aggregate sample. The equipment used was Shimadzu model XRD - 7000. The specimen with a particle size of less than $0.15 \mathrm{~mm}$ were submitted to the test, using $\mathrm{Cu}-\mathrm{K \alpha}$ radiation, with accelerated voltage $40 \mathrm{kV}$ and $30 \mathrm{~mA}$ current, with a $2 \theta$ scan of $5^{\circ}$ to $80^{\circ}$ and speed of $5^{\circ} \mathrm{min}$. 


\subsection{Mixes proportions}

Table 2 presents the mortars specification. Table 3 shows the mixes compositions.

Table 2. Mixes' composition.

\begin{tabular}{ccc}
\hline Mixes & Mixes' composition & Recycled Aggregates Condition \\
\hline FNCN & Fine Natural Aggregate + Coarse Natural Aggregate & - \\
\hline FNCRD & Fine Natural Aggregate + Coarse Recycled Aggregate & Dried \\
\hline FNCRW & Fine Natural Aggregate + Coarse Recycled Aggregate & Washed \\
\hline FNCRS & Fine Natural Aggregate + Coarse Recycled Aggregate & Saturated \\
\hline FRCND & Fine Recycled Aggregate + Coarse Natural Aggregate & Dried \\
\hline FRCNW & Fine Recycled Aggregate + Coarse Natural Aggregate & Washed \\
\hline FRCRD & Fine Recycled Aggregate + Coarse Recycled Aggregate & Dried \\
\hline FRCRW & Fine Recycled Aggregate + Coarse Recycled Aggregate & Washed \\
\hline
\end{tabular}

Table 3. Mix proportions of concrete $(\mathrm{kg} / \mathrm{m} 3)$.

\begin{tabular}{ccccccc}
\hline Mixes & Cement & Water & Natural sand & Recycled sand & Natural gravel & Recycled gravel \\
\hline FNCN & 199.7 & 76.8 & 1716.8 & - & 533.8 & - \\
\hline FNCRD & 197.4 & 75.9 & 1696.8 & - & - & 440.3 \\
\hline FNCRW & 197.4 & 75.9 & 1696.8 & - & - & 440.3 \\
\hline FNCRS & 197.4 & 75.9 & 1696.8 & - & - & 440.3 \\
\hline FRCND & 198.6 & 76.4 & - & 1649.6 & 530.8 & - \\
\hline FRCNW & 198.6 & 76.4 & - & 1649.6 & 530.8 & - \\
\hline FRCRD & 196.3 & 75.5 & - & 1630.6 & - & 437.9 \\
\hline FRCRW & 196.3 & 75.5 & - & 1630.6 & - & 437.9 \\
\hline
\end{tabular}

It was investigated the use of fine and coarse recycled aggregates under three conditions: dried, washed and saturated. In order to verify the influence of its condition on the properties of the concrete blocks produced.

Dried condition: the recycled aggregates were introduced into the mixture as they are produced in the plant.

Washed condition: the recycled aggregates were washed for removal of the pulverulent material, the sieve used in the wash was \#200 $(0.075 \mathrm{~mm})$. After that the recycled aggregates were dried before adding in the mix.

Saturated condition: the recycled aggregates were immersed in water for 24 hours before being mixed for the production of the blocks. However, the saturated fine recycled aggregates did not obtain the required consistency, discarding this possibility. Thus, only the recycled coarse aggregates were saturated.

\subsection{Tests}

The production of the blocks was performed in a real scale inside a precast plant. The dimensional tolerance analysis of the blocks was according to NBR 9781 [32]. The standard refers to the dimensions of the block as 10x20x6 cm (width $\mathrm{x}$ length $\mathrm{x}$ thickness), admitting $3 \mathrm{~cm}$ of tolerance.

The compressive strength was evaluated at the ages of 7, 14, 28 and 365 days with six blocks for each sample, according to NBR 9781 [32]. The standard requires that two auxiliary boards for the compressive strength test must be circular, with a diameter of $85 \mathrm{~mm}$ and a minimum thickness of $20 \mathrm{~mm}$, made of steel.

Water absorption at 28 and 365 days with three blocks of each composition was analyzed. For the anaysis of water absorption, the test was carried out according to NBR 9781 [32].

\subsection{Evaluation of real-scale interlocked blocks}

To evaluate the performance in the field, a real-scale experimental stretch of interlocked paving was performed with the blocks produced. The prototype was built in the Recycling Plant, which provided the recycled aggregates. The segment was divided into parts for evaluation of each composition, in order to analyze the functional performance of the blocks. 


\section{RESULTS AND DISCUSSIONS}

\subsection{Aggregates characterization}

Figure 1 shows the size distribution curve of the sand. The recycled sand presented a curve of differentiated size of particles, which enhance the packaging.

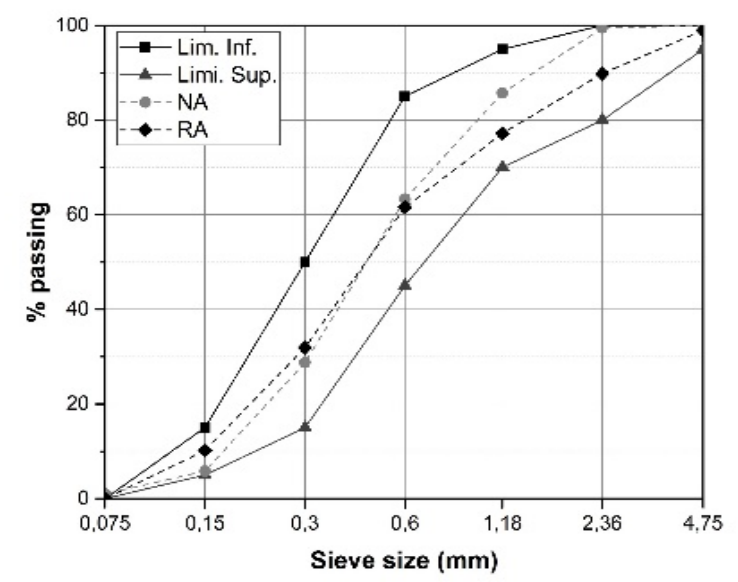

Figure 1. Size distribution of natural and recycled fine aggregate. NA = Natural Aggregate. RA = Recycled Aggregate.

The size distribution of the coarse recycled aggregate is similar to that the natural aggregate, as can be observed in Figure 2. The compactness of the concrete affects directly the mechanical behavior. It can be observed that the recycled sand presents a better size distribution, which could improve the mechanical resistance.

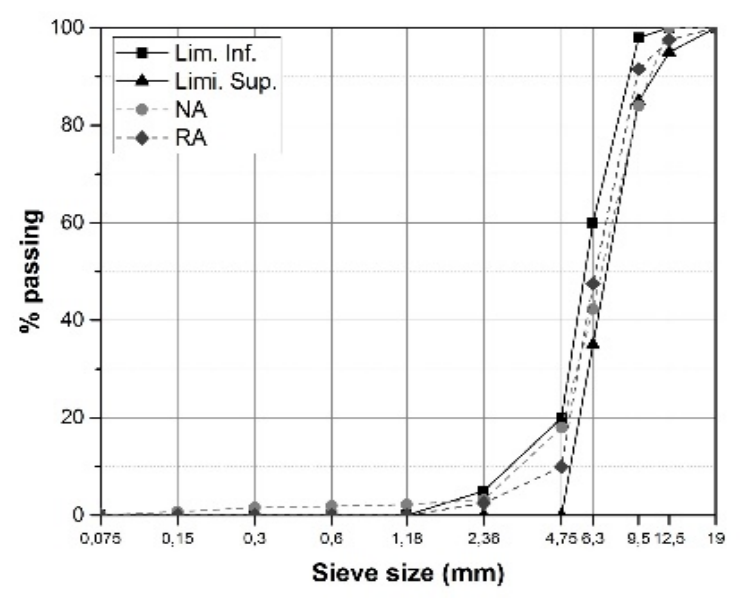

Figure 2. Size distribution of natural and recycled coarse aggregate. NA = Natural Aggregate. RA = Recycled Aggregate.

Table 4 shows the results of the physical tests of natural and recycled fine aggregates. The density of the recycled aggregate is lower when compared to the natural aggregate, while the water absorption has significantly higher values. These characteristics, in general, are attributed to the old mortar adhered to the particle [21], [22], [33]. 
Table 4. Fine aggregates characteristics.

\begin{tabular}{ccc}
\hline & Natural Sand & Recycled Sand \\
\hline Fineness Modulus & 2.17 & 2.27 \\
\hline Bulk density $\left(\mathrm{kg} / \mathrm{m}^{3}\right)$ & 1490 & 1440 \\
\hline Dry density $\left(\mathrm{kg} / \mathrm{m}^{3}\right)$ & 2620 & 2510 \\
\hline Fine content $(\%)$ & 1.00 & 7.00 \\
\hline Surface area & 1.227 & 3.547 \\
\hline
\end{tabular}

In general, recycled aggregates present lower density than natural aggregates. This fact could be attributed to their heterogeneity due to the waste's composition. Thus, the density of the recycled materials tends to be lower than those of conventional mortar and concrete [8].

According to the standard for determining the content of powdery materials in aggregates (NBR 7219) [34] the maximum values of materials passing through the $0.075 \mathrm{~mm}$ sieve is $5 \%$. A higher content of fine particles in the mix can affect the required kneading water, which implies a reduction in the mechanical resistance of the concrete produced, as well as, a decrease in abrasion resistance [35]. This may affect negatively the concrete, due to the higher water consumption and the presence of clay minerals.

In this research, the recycled fine aggregates obtained $7 \%$ of particles passing through the \#200 sieve. This amount of dust can affect the bond between the aggregate and the paste, which may weaken the transition zone. Washing is a technique used to remove the pulverulent material from the recycled aggregates, since the content of fines correlates directly with the water absorption of the aggregates, due to the greater surface area of the materials. The reduction of the very fines particles decreases the water/cement ratio, which can influence the workability and improve the properties of the hardened concrete.

The results obtained in the laser granulometry (BET) test for the fines material showed the recycled aggregates with greater surface area, corroborating with other studies [19], [36]. This could be explained by a surface more irregular and porous. As a consequence of this, the recycled aggregate can provide a strengthening of the interfacial transition zone between the cementitious matrix and the aggregates.

Table 5 presents the results of the tests performed with the coarse aggregates. The Los Angeles abrasion resistance analyses the quality of the material. It is identified the resistance to fragmentation by shock and friction of the particles. The resistance of the recycled aggregate is not the same as the material that originated it, because the crushing process weakens the particle, which causes the cracks inside the recycled aggregate.

Table 5. Coarse aggregates characteristics.

\begin{tabular}{ccc}
\hline & Natural Gravel & Recycled Gravel \\
\hline Bulk density $\left(\mathrm{kg} / \mathrm{m}^{3}\right)$ & 1390 & 1160 \\
\hline Dry density $\left(\mathrm{kg} / \mathrm{m}^{3}\right)$ & 2610 & 2060 \\
\hline Fine content $(\%)$ & 1.00 & 4.00 \\
\hline Los Angeles & 25 & 49 \\
\hline Water absorption $(\%)$ & 1.00 & 8.00 \\
\hline
\end{tabular}

Table 6 shows the chemical analyzes of the natural and recycled aggregates.

Table 6. X Ray fluorescence test results.

\begin{tabular}{cccc}
\hline Samples & Al2O3 & CaO & Fe2O3 \\
\hline NA & 12.10 & 4.65 & 8.99 \\
RA & 10.18 & 29.80 & 8.90 \\
\hline
\end{tabular}

NA = Natural Aggregate. RA = Recycled Aggregate.

The recycled aggregates present a chemical composition similar to that found in other studies that analyzed the recycled aggregates [22], [37], [38].

The main elements found in the recycled aggregates are oxides of silica, calcium, aluminum and iron, originating mainly from hydrated cementitious compounds (concretes and mortars), as well as materials of ceramic origin [39]. It is important 
to highlight the presence of sulfur oxide (SO3) in the recycled aggregate, since this chemical element can cause gradual loss of mechanical resistance and affect the durability of materials produced with this type of aggregates [40].

The results of the images obtained by SEM for the natural and recycled aggregates are shown in Figures 3 and 4 .

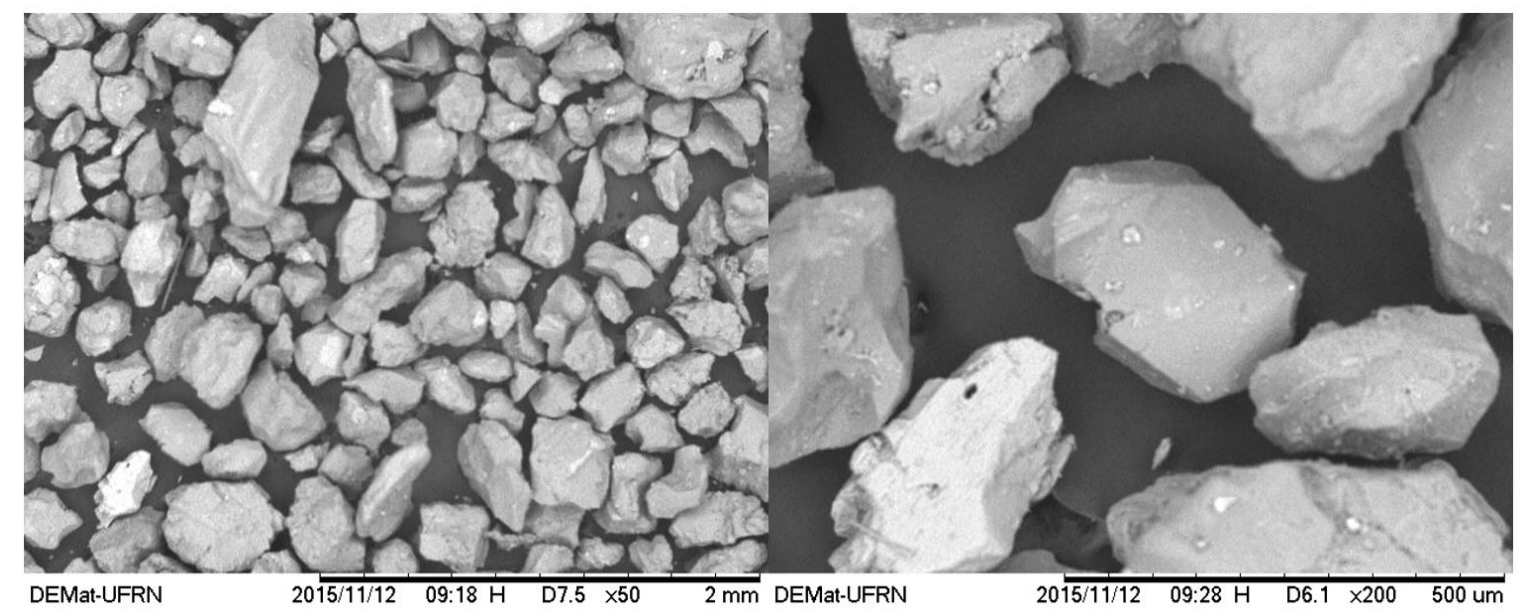

Figure 3. SEM image of obtained natural aggregate sample.

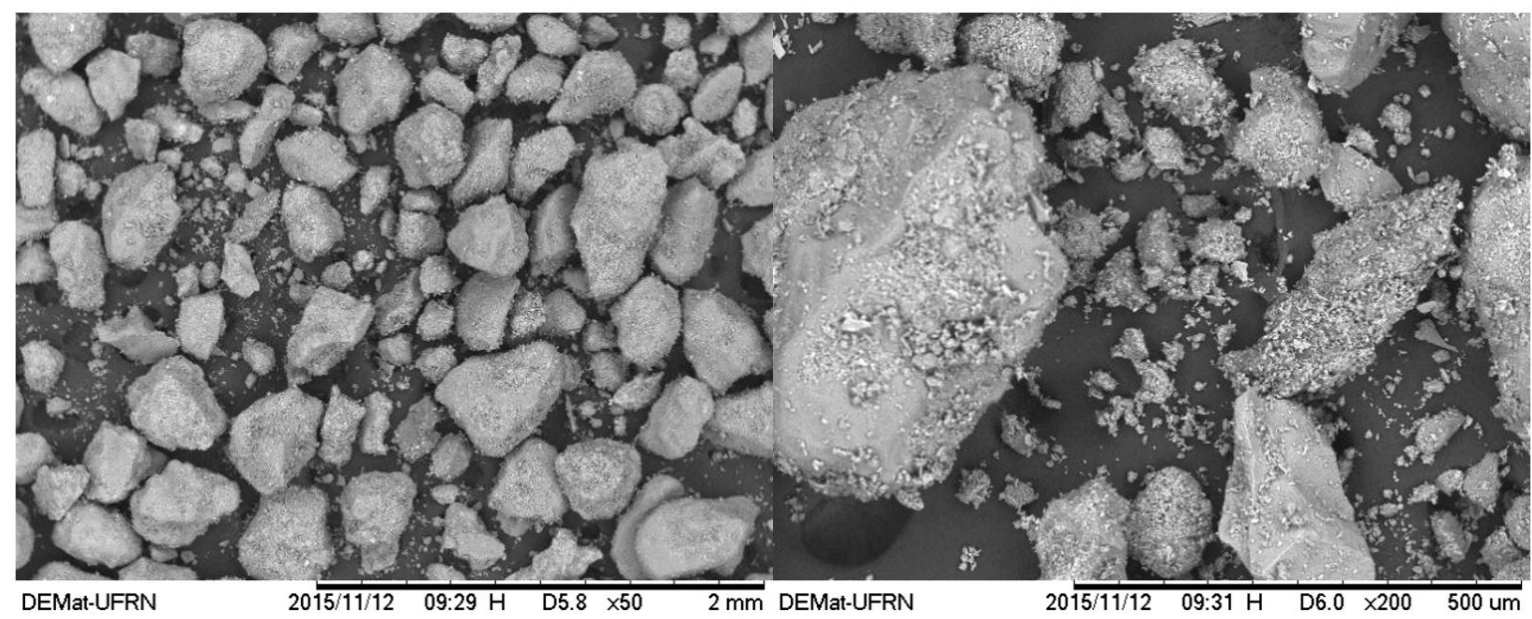

Figure 4. SEM image of obtained recycled aggregate sample.

The particles of the natural aggregates present regular texture and size. However, the recycled aggregates present irregular shape and size, with more defined edges, which can be attributed to the CDW crushing process to obtain these aggregates.

The particles of the recycled aggregates also present a roughened porous surface, which may be due to the old mortar adhered to the particles, corroborating with the micrographs presented by other authors [23], [41], [42]. The rough surface of the particle can improve the adhesion between the particles and the cementitious matrix, increasing the mechanical resistance.

Figure 5 shows the main crystalline phases of the recycled aggregate. In agreement with the results of the chemical composition, the recycled aggregate presents silicates (quarzt; feldspars-albite and microcline; mica-muscovite and clay mineral-kaolinite), sulfates (gypsite) and carbonates (calcite).

The mineralogical composition of the recycled aggregate originated from the variety of original components (concrete, mortar, and ceramics), and is consistent with other published studies [10], [23], [24], [27], [39], [40]. 


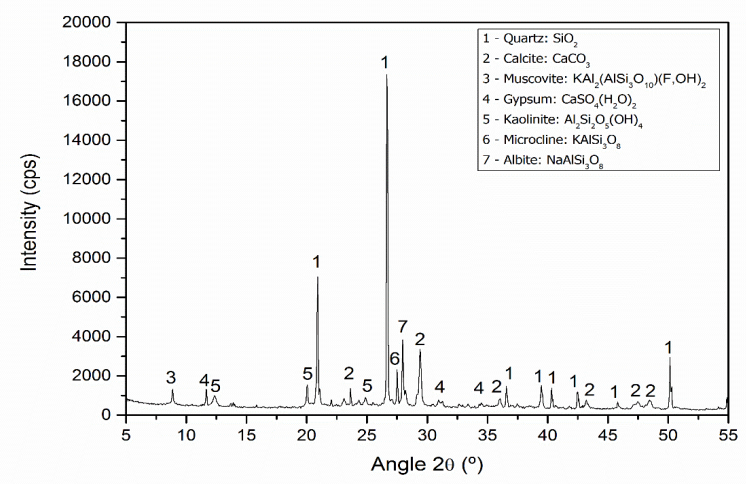

Figure 5. Diffractogram of the recycled aggregate.

\subsection{Blocks characterization}

Table 7 present the results obtained of water absorption and compressive strength of the concrete blocks. These results are discussed individually in the following sections.

Table 7. Properties of concrete blocks.

\begin{tabular}{ccccccccccccc}
\hline Samples & \multicolumn{3}{c}{ Water absorption (\%) } & \multicolumn{5}{c}{ Compressive strength (MPa) } \\
\hline FNCN & $28 \mathrm{~d}$ & SD & $365 \mathrm{~d}$ & SD & $7 \mathrm{~d}$ & SD & $14 \mathrm{~d}$ & SD & $28 \mathrm{~d}$ & SD & $365 \mathrm{~d}$ & SD \\
\hline FNCRD & 4.0 & 0.1 & 2.0 & 0.14 & 10.97 & 0.25 & 11.6 & 0.88 & 13.12 & 0.87 & 18.1 & 0.33 \\
\hline FNCRW & 7.0 & 0.48 & 6.0 & 0.24 & 7.41 & 0.69 & 9.26 & 1.01 & 9.72 & 0.77 & 14.28 & 0.55 \\
\hline FNCRS & 6.0 & 0.158 & 5.0 & 0.38 & 9.11 & 0.38 & 10.66 & 0.98 & 12.22 & 0.54 & 16.58 & 0.48 \\
\hline FRCND & 8.0 & 0.25 & 5.0 & 0.54 & 8.2 & 0.54 & 10.6 & 0.65 & 13.56 & 0.59 & 19.23 & 0.59 \\
\hline FRCNW & 3.0 & 0.36 & 2.0 & 0.41 & 11.57 & 0.87 & 12.96 & 0.67 & 15.2 & 0.67 & 24.35 & 0.77 \\
\hline FRCRD & 4.0 & 0.58 & 3.0 & 0.33 & 15.71 & 0.59 & 17.35 & 0.77 & 22.16 & 0.55 & 27.34 & 0.99 \\
\hline FRCRW & 6.0 & 0.12 & 5.0 & 0.21 & 9.85 & 0.25 & 10.29 & 0.88 & 11.13 & 0.34 & 15.34 & 1.05 \\
\hline
\end{tabular}

Legenda: $\mathrm{d}=$ days; $\mathrm{SD}=$ Standard deviation

\subsubsection{Water absorption}

The Brazilian standard NBR 9781 [32] based on ASTM C 936-1 [43], requires an average water absorption results of less than or equal to $5 \%$, with individual values not exceeding $7 \%$ being accepted. Figure 6 shows the values of the absorption rate of the blocks at 28 and 365 days.

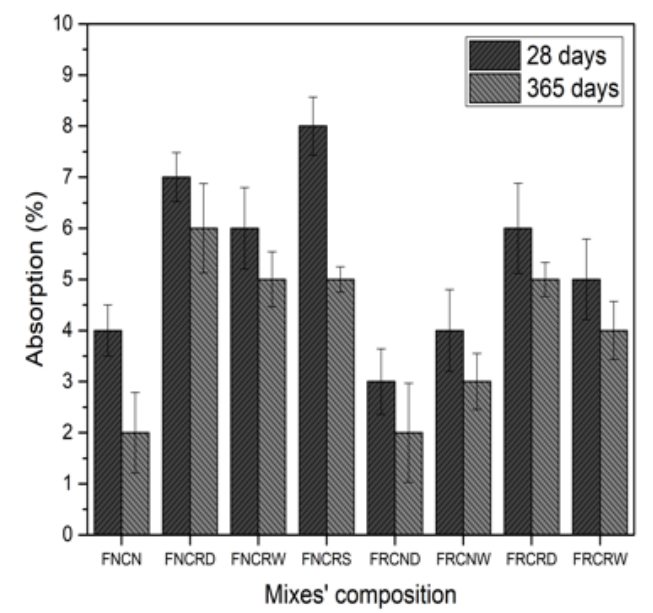

Figure 6. Absorption of water from the blocks at 28 and 365 days. 
The samples with dried recycled sand and natural coarse aggregate obtained the lowest rate of water absorption at 28 days. The recycled sand with high powder content may have caused a better packaging of the particles in the concrete, which contributes to a better compactness of the block. The continuous size distribution of recycled sand may have influenced a lower rate of water absorption.

At 28 days, the concrete blocks produced with washed recycled aggregate achieved the requirements of the standard, obtained the water absorption rate less than or equal to $5 \%$ beyond the reference. On the other hand, the blocks produced with natural sand and recycled coarse aggregates obtained an average water absorption higher than 5\%.

The reference block had the lowest volume of voids and, consequently, the highest density. Blocks with natural sand and dried coarse recycled aggregate showed a higher absorption rate as greater voids indices. However, the block with natural sand and washed coarse recycled obtained a lower rate of water absorption. It is emphasized that the washing procedure changed the water absorption rate of the block with coarse recycled aggregate.

The blocks produced with recycled sand presented water absorption similar to the block with natural aggregates. As for the blocks with washed fine recycled aggregates, it was observed that they obtained higher absorption results than the blocks with dried recycled.

\subsubsection{Compressive strength}

Figure 7 shows the results obtained in the compressive strength of all specimens at 7, 14, 28 and 365 days. The best mechanical strength at 28 and 365 days was the modified concrete produced with washed recycled sand and natural coarse aggregate.

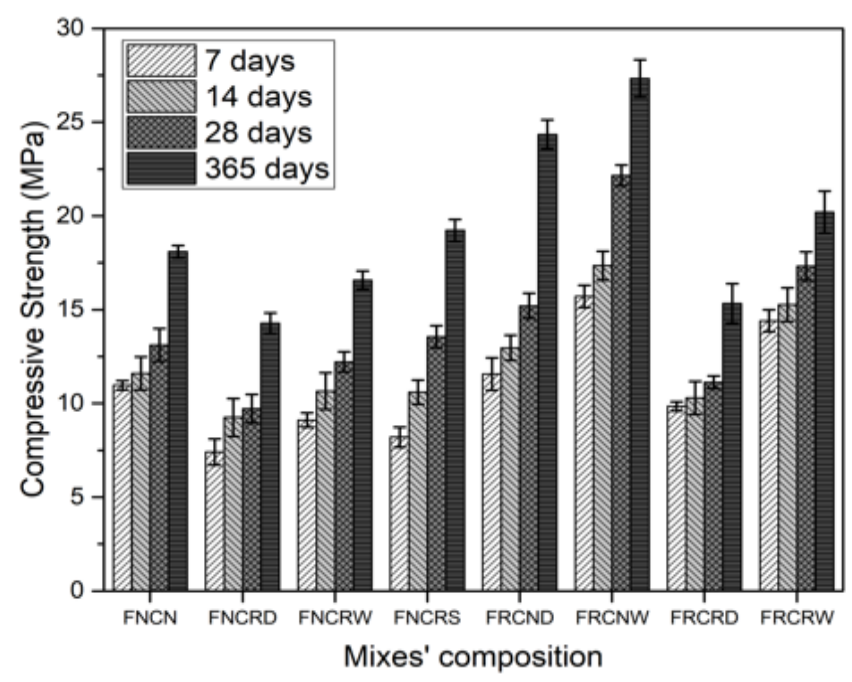

Figure 7. Comparison of the compressive strength of the blocks tested.

Blocks with recycled sand presented a better mechanical performance compared to the reference concrete block. Vieira and Dal Molin [44] also followed the same trend. There was an increase in the compressive strength with $100 \%$ recycled sand and $0 \%$ recycled coarse aggregate. This better performance could also be attributed to a chemical factor due to a possible pozzolanic effect of the very fine material.

Figure 8 presents the results of the compressive strength of the blocks by the fine and coarse aggregates used. Figure 8 shows the increment in compressive strength of the blocks produced with fine recycled aggregates when compared to the others. 


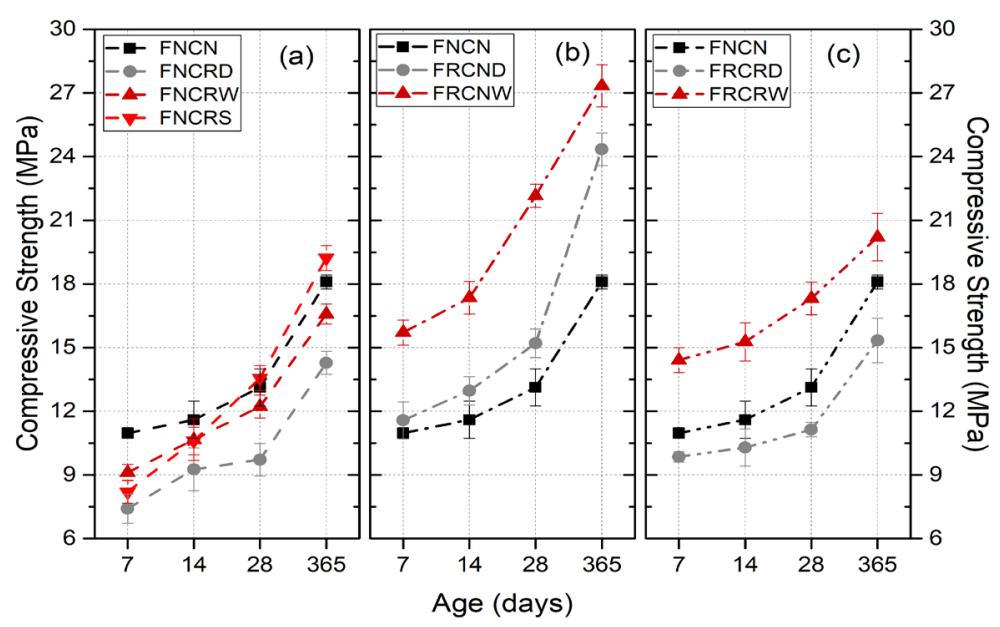

Figure 8. Compressive strength of the blocks tested by fine and coarse aggregates.

Leite et al. [45] also found that the concrete blocks with fine recycled aggregates presented pozzolanic activity indexes, which may be associated to the increase of compressive strength in concretes with high content of sand replacement at advanced ages. Khatib [17] verified the increase of compressive strength from 28 to 90 days in concrete with fine recycled aggregate and justified this effect by the possible pozzolanic activity of the fines.

Cabral et al. [19] also verified that the use of the fine recycled aggregate increased the compressive strength of the concrete. Possible reasons for this effect were the pozzolanic reactions, which improve the interfacial transition zone of the matrix, the roughness of the particles. It reinforces the bonds between the cement paste and the aggregates, and the water absorbed by the particles may be available for continuous hydration of the cement. These results were also pointed out by other authors [12], [18], [46].

In general, the mechanical strength present significant improvements with the incorporation of fines, due to both the filler effect, due to a filling of voids by the very fine particles, which increase the compactness of the concrete. Braga et al. [15] pointed out that with the replacement of fine aggregate, in addition to the filler effect, it occurs the hydraulic effect of non-hydrated cement on the recycled material. Thus, the strength may depend on the type of fines and the amount of replacement.

From the results obtained in this research and from other authors [20], [47] it is evident that the use of recycled aggregates in concrete does not significantly affect the compressive strength. However, it is essential to consider the characterization and treatment of recycled aggregates. Leite et al. [45] found that the use of recycled aggregate in concrete replacing the natural aggregate, mainly for low water/cement ratios is feasible.

The concrete produced with coarse recycled aggregates presented a decrease of compressive strength when compared to the reference blocks. At 365 days, obtained reduction of $21 \%$ and $8 \%$, with dried and washed aggregates, respectively. Vieira and Dal Molin [44] and Poon and Chan [2] also found a reduction of mechanical resistance with the replacement of $100 \%$ of coarse recycled aggregates.

For the manufacture of precast concrete a lower water/cement factor is required, which may present difficulty in the workability of the mixture. Thus, it is necessary to take into consideration that recycled aggregates can absorb part of the kneading water. Thus, the decrease of mechanical strength with recycled aggregate can be attributed to the water/cement ratio, the higher water absorption and the lower density of the recycled aggregates.

The performance of the concrete with recycled aggregate depends mainly on the cement consumption and the water/cement ratio. The decrease of compressive strength can be attributed to factors such as low resistance and density of the recycled aggregate and higher water absorption, which implies negatively in the workability and consequently in the mechanical resistance.

\subsubsection{Analysis of the experimental section}

The interlocking pavement road was analyzed after one year of being used. In general, the pavement indicated good functionality and its in use, supporting the demanded load. 
Visually, in the reference blocks can notice no evidence of broken edges. The blocks produced with recycled fine aggregate also exhibit similar behavior as the reference block. However, blocks produced with coarse recycled aggregate presented higher damages.

In order to evaluate the mechanical performance of the specimens, the compressive strength was analyzed in blocks with total replacement of fine and coarse recycled aggregates (FRCRD / FRCRW), the results are presented in Figure 9. It was observed a reduction in the mechanical performance. Blocks produced with dried recycled aggregates obtained an average of $9.87 \mathrm{MPa}$, a reduction of $34.2 \%$ when compared to the results obtained of the same samples kept 365 days inside the laboratory conditions.

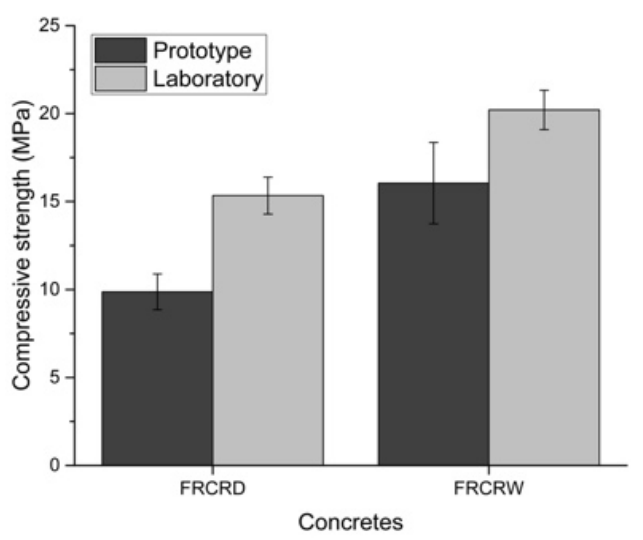

Figure 9. Comparison between the compressive strength of the blocks produced in the laboratory and in the field.

The blocks produced with washed recycled aggregates presented a compressive strength of $16.05 \mathrm{MPa}$, which means a reduction of $27 \%$ according to the resistance at 365 days. The decrease in mechanical strength can be attributed to the load borne by the parts during this period. In general, the pavement indicated good functionality and is in use in the plant itself, supporting the demanded load.

\section{CONCLUSIONS}

Modified blocks with the incorporation of recycled sand presented a better performance comparing to the reference concrete. On the other hand, blocks with the incorporation of coarse aggregates presented several drawbacks.

Blocks produced with washed recycled aggregates presented better results in all properties. The removal of the powdery material provided greater compressive strength.

The visual aspects of the modified blocks in the experimental full-scale presented slightly more damaged than the reference blocks.

Blocks produced with recycled aggregates could be used for low-load road, such as sidewalks, gardens and streets.

\section{ACKNOWLEDGEMENTS}

The authors thanks the partnership of the recycling industry Usina Duarte and the precast company Pavlocos.

\section{REFERENCES}

[1] Associação Brasileira para Reciclagem de Resíduos da Construção Civil e Demolição. "Recycling of Construction and Demolition Waste in Brazil, Statistics Reports 2014-2015.” São Paulo: ABRECON, 2015. Accessed: Feb. 15, 2018. [Online]. Available: http://www.abrecon.org.br/pesquisa_setorial/

[2] C. S. Poon and D. Chan, "Feasible use of recycled concrete aggregates and crushed clay brick as unbound road sub-base," Constr. Build. Mater., vol. 20, pp. 578-585, 2006.

[3] J. Yang, Q. Du, and Y. Bao, "Concrete with recycled concrete aggregate and crushed clay bricks," Constr. Build. Mater., vol. 25, pp. 1935-1945, 2011. 
[4] M. N. Soutsos, K. Tang, and S. G. Millard, "Use of recycled demolition aggregate in precast products, phase II: concrete paving blocks," Constr. Build. Mater., vol. 25, pp. 3131-3143, 2011.

[5] F. Lopez-Gayarre, C. Lopez-Colina, M. A. Serrano, and A. Lopez-Martínez, "Manufacture of concrete kerbs and floor blocks with recycled aggregate from C\&DW," Constr. Build. Mater., vol. 40, pp. 1193-1199, 2013.

[6] M. M. Sabai, M. G. D. M. Cox, R. R. Mato, E. L. C. Egmond, and J. J. N. Lichtenberg, "Concrete block production from construction and demolition waste in Tanzania," Resour. Conserv. Recycling, vol. 72, pp. 9-19, 2013.

[7] J. Xiao, L. Li, L. Shen, and C. S. Poon, "Compressive behaviour of recycled aggregate concrete under impact loading," Cement Concr. Res., vol. 71, pp. 46-55, 2015.

[8] C. Rodriguez et al., "The incorporation of construction and demolition wastes as recycled mixed aggregates in non-structural concrete precast pieces," J. Clean. Prod., vol. 127, pp. 152-161, 2016.

[9] F. Ozalp, H. D. Yilmaz, M. Kara, O. Kaya, and A. Sahin, "Effects of recycled aggregates from construction and demolition wastes on mechanical and permeability properties of paving stone, kerb and concrete pipes," Constr. Build. Mater., vol. 110, pp. 17-23, 2016.

[10] M. Contreras et al., "Recycling of construction and demolition waste for producing new construction material (Brazil case study)," Constr. Build. Mater., vol. 123, pp. 594-600, 2016.

[11] C. S. G. Penteado, E. V. Carvalho, and R. C. C. Lintz, "Reusing ceramic tile polishing waste in paving block manufacturing," J. Clean. Prod., vol. 112, pp. 514-520, 2016.

[12] L. Evangelista and J. Brito, "Durability performance of concrete made with fine recycled concrete aggregates," Cement Concr. Compos., vol. 32, no. 1, pp. 9-14, 2010.

[13] M. A. Leite, "Evaluation of mechanical properties of concretes produced with recycled aggregates of construction and demolition wastes," Ph.D. dissertation, Univ. Fed. Rio Grande do Sul, Porto Alegre, 2001.

[14] M. Bravo, J. Brito, J. Pontes, and L. Evangelista, "Mechanical performance of concrete made with aggregates from construction and demolition waste recycling plants," J. Clean. Prod., vol. 99, pp. 59-74, 2015.

[15] M. Braga, J. Brito, and R. Veiga, "Reduction of the cement content in mortars made with fine concrete aggregates," Mater. Struct., vol. 47, no. 1, pp. 171-182, 2014.

[16] C. Medina, W. Zhu, and T. Howind, "S_anchez de Rojas, M.I., Frías, M. Influence of mixed recycled aggregate on the physical e mechanical properties of recycled concrete," J. Clean. Prod., vol. 68, pp. 216-225, 2014.

[17] J. M. Khatib, "Properties of concrete incorporating fine recycled aggregate," Cement Concr. Res., vol. 35, no. 4, pp. 763-769, 2005.

[18] S. Laserna and J. Montero, "Influence of natural aggregates typology on recycled concrete strength properties," Constr. Build. Mater., vol. 115, pp. 78-86, 2016.

[19] A. E. B. Cabral, V. Schalch, D. C. C. Dal Molin, and J. L. D. Ribeiro, "Mechanical properties modeling of recycled aggregate concrete," Constr. Build. Mater., vol. 24, no. 4, pp. 421-430, 2010.

[20] P. S. Lovato, E. Possan, D. C. C. Dal Molin, A. Masuero, and J. Ribeiro, "Modeling of mechanical properties and durability of recycled aggregate concretes," Constr. Build. Mater., vol. 26, pp. 437-447, 2012.

[21] M. Etxeberria, E. Vázquez, A. Marí, and M. Barra, "Influence of the amount of recycled coarse aggregates and production process on properties of recycled aggregate concrete," Cement Concr. Res., vol. 27, no. 5, pp. 735-742, 2006.

[22] M. Pepe, R. D. Toledo Fo., E. A. Koenders, and E. Martinelli, "Alternative processing procedures for recycled aggregates in structural concrete," Constr. Build. Mater., vol. 69, pp. 124-132, 2014.

[23] L. Evangelista, M. Guedes, J. de Brito, A. C. Ferro, and M. F. Pereira, "Physical, chemical and mineralogical properties of fine recycled aggregates made from concrete waste," Constr. Build. Mater., vol. 86, pp. 178-188, 2015.

[24] F. Rodrigues, M. Carvalho, L. Evangelista, and J. Brito, "Physical-chemical and mineralogical characterization of fine aggregates from construction and demolition waste recycling plants," J. Clean. Prod., vol. 52, pp. 438-445, 2013.

[25] C. S. Poon, S. C. Kou, and L. Lam, "Use of recycled aggregates in molded concrete bricks and blocks," Constr. Build. Mater., vol. 16, pp. 281-289, 2002.

[26] Associação Brasileira de Normas Técnicas, Aggregates - Sampling, NBR NM 26, 2001.

[27] Associação Brasileira de Normas Técnicas, Aggregates - Sieve Analysis of Fine and Coarse Aggregates, NBR NM $248,2003$.

[28] Associação Brasileira de Normas Técnicas, Aggregate Determination of the Unit Weight and Air-void Contents, NBR NM 45, 2006.

[29] Associação Brasileira de Normas Técnicas, Fine Aggregates - Determination of the Bulk Specific Gravity and Apparent Specific, NBR NM 52, 2009.

[30] Associação Brasileira de Normas Técnicas, Coarse Aggregates - Determination of the Bulk Specific Gravity, Apparent Specific Gravity and Water Absorption, NBR NM 53, 2009.

[31] Associação Brasileira de Normas Técnicas, Small-size Coarse Aggregates - Test Method for Resistence to Degradation by Los Angeles Machine, NBR NM 51, 2001.

[32] Associação Brasileira de Normas Técnicas, Concrete Paving Units - Specification and Test Methods, NBR $9781,2013$. 
[33] M. S. Juan and P. A. Gutiérrez, "Study on the influence of attached mortar content on the properties of recycled concrete aggregate," Constr. Build. Mater., vol. 23, no. 2, pp. 872-877, 2009.

[34] Associação Brasileira de Normas Técnicas, Aggregates - Determination of Powder Content, NBR 7219, 1987.

[35] P. K. Mehta and P. J. M. Monteiro, Concreto: Microestrutura, Propriedades e Materiais, 3rd ed. São Paulo: Ibracon, 2013.

[36] R. Silva, J. Brito, and R. K. Dhir, "Performance of cementitious rendering and masonry mortars containing recycled aggregates from construction and demolition wastes," Constr. Build. Mater., vol. 105, pp. 400-415, 2016.

[37] E. Limbachiya and A. Marrocchino, "Kouloris. Chemical-mineralogical characterization of coarse recycled concrete aggregate," Waste Manag., vol. 27, pp. 201-208, 2007.

[38] M. Stefanidou, E. Anastasiou, and G. Filikas, "Recycled sand in lime-based mortars," Waste Manag., vol. 34, pp. $2595-2602$, 2014.

[39] S. C. Angulo, C. Ulsen, V. M. John, H. Kahn, and M. A. Cincotto, "Chemical-mineralogical characterization of C\&D waste recycled aggregates from São Paulo, Brazil," Waste Manag., vol. 29, pp. 721-730, 2009.

[40] P. S. Martínez, M. G. Cortina, F. F. Martínez, and A. R. Sánchez, "Comparative study of three types of fine recycled aggregates from construction and demolition waste (CDW), and their use in masonry mortar fabrication," J. Clean. Prod., vol. 118, pp. 162-169, 2016.

[41] M. S. K. Behera, A. K. Bhattacharyya, R. Minocha, S. Deoliya, and S. Maiti, "Recycled aggregate from C\&D waste \& its use in concrete. A breakthrough towards sustainability in construction sector: a review," Constr. Build. Mater., vol. 68, pp. 501-516, 2014.

[42] J. Li and E. Yang, "Macroscopic and microstructural properties of engineered cementitious composites incorporating recycled concrete fines," Cement Concr. Compos., vol. 78, pp. 33-42, 2017.

[43] American Society for Testing and Materials, Specification for Solid Concrete Interlocking Paving Units, ASTM 936-1, 2016.

[44] G. Vieira and D. Dal Molin, "Resistência e durabilidade de concretos produzidos com agregados reciclados provenientes de resíduos de construção e demolição," Eng. Civ. UM., vol. 19, pp. 5-18, 2004.

[45] F. C. Leite, R. S. Motta, K. L. Vasconcelos, and L. Bernucci, "Laboratory evaluation on recycled construction and demolition waste for pavements," Constr. Build. Mater., vol. 25, pp. 2972-2979, 2011.

[46] V. Corinaldesi and G. Moriconi, "Behaviour of cementitious mortars containing different kinds of recycled aggregate," Constr. Build. Mater., vol. 23, no. 1, pp. 289-294, 2009.

[47] J. Brito, R. K. Dhir, and R. V. Silva, "Properties and composition of recycles aggregates from construction and demolition waste suitable for concrete production," Constr. Build. Mater., vol. 65, pp. 201-217, 2015.

Author contributions: C.M.P. and R.S.F. performed the experiments, data curation, formal analysis, writing. The analyses of the tests and interpretation of the results were developed by C.M.P., M.P.D., E.F.A. and R.S.F. The original draft of this paper was written by C.M.P. The review and editing were performed by M.P.D., E.F.A. and R.S.F. All authors have read and agreed to the published version of the manuscript.

Editors: Jose Tadeu Balbo, José Luiz Antunes de Oliveira e Sousa, Guilherme Aris Parsekian. 